\title{
The secular evolution of the reverse weathering sink in the global $\mathrm{Li}$ cycle
}

\author{
MATtheW S. FANTLE ${ }^{1 *}$, Ben DAVis BARNES ${ }^{1}$, \\ ELIZABETH ANDREWS ${ }^{1,2}$ \\ ${ }^{1}$ Dept. of Geosciences, Penn State University, University \\ Park, PA 16802, USA (*mfantle@psu.edu) \\ ${ }^{2}$ Hydrologic Science and Engineering, Dept. of Geology and \\ Geological Engineering, Colorado School of Mines, \\ Golden, CO 80401
}

The global cycling of $\mathrm{Li}$ in the modern ocean is driven primarily by continental chemical weathering and hydrothermal input fluxes, balanced by sinks associated with oceanic crust alteration and the authigenic precipitation of alumino-silicate clays (i.e., "reverse weathering"). Seawater $\delta^{7} \mathrm{Li}$, as constrained by planktonic foraminiferal tests, has evolved significantly over the last $70 \mathrm{Ma}$, increasing $9 \%$ to modern values over the Cenozoic. This increase has been hypothesized to reflect long-term changes in continental weathering [1]. While subsequent modeling efforts suggested that shifts in marine Li sinks could feasibly perturb seawater $\delta^{7} \mathrm{Li}[2]$, the mechanism remains unclear.

In this contribution, we propose a novel mechanism for a reverse weathering-driven forcing of seawater $\delta^{7} \mathrm{Li}$. Deep-sea sedimentary pore fluid data suggest that clay authigenesis occurs in carbonate-rich sediments, and that these sediments can represent significant sinks of $\mathrm{Li}$ from the global ocean (estimated at a maximum of $<2 \cdot 10^{10}$ moles $\mathrm{Li} / \mathrm{a}$ ). The $\mathrm{Li}$ isotopic data indicate that clay authigenesis occurs at depth in the sedimentary column, while modeling efforts suggest that deep mineral formation (and consequent isotopic fractionation of $\mathrm{Li}$ ) changes the effective fractionation factor via isotopic distillation. Ultimately, the burial of reactive sediment, ostensibly biogenic silica, has the potential to drive variability in seawater $\delta^{7} \mathrm{Li}$.

We test the sensitivity of seawater $\delta^{7} \mathrm{Li}$ to secular trends in global $\mathrm{Li}$ diagenetic fluxes using oceanic box models and reactive transport models of the sedimentary section. Deep-sea sedimentary records over the Cenozoic support the hypothesis that the fluxes associated with reverse weathering may have contributed to the observed trends in $\delta^{7} \mathrm{Li}$. Ultimately, the secular variability in the reverse weathering sink has the potential to impact the reconstruction of the continental weathering flux based on $\delta^{7} \mathrm{Li}$ proxy records.

[1] Misra and Froelich (2012) Science 335, 818-823. [2] Li and West (2014) Earth Planet. Sci. Lett. 401, 284-293. 